\title{
Uma experiência de insercão da Paleontologia no ensino fundamental em díferentes regiões do Brasil
}

\author{
AN EXPERIENCE OF INSERTION OF PALEONTOLOGY IN ELEMENTARY SCHOOL IN DIFFERENT REGIONS OF BRAZIL \\ Tarsila Novais ${ }^{1, *}$, Alcemar Rodrigues Martelloº ${ }^{2}$, Luciane Carvalho Oleques ${ }^{3}$, Luciano Artemio Leal ${ }^{1}$ e Átila Augusto Stock da-Rosa ${ }^{4}$ \\ 1 Universidade Estadual do Sudoeste da Bahia, campus Jequié, Jequiezinho, Jequié - BA, *tarsila_novais@hotmail.com; \\ 2 Universidade Estadual do Paraná, campus União da Vitória, União da Vitória - PR. \\ 3 Instituto Federal Farroupilha, Campus Santa Rosa, Santa Rosa - RS. \\ 4 Universidade Federal de Santa Maria, Laboratório de Estratigrafia e Paleobiologia, Departamento de Geociências, Santa Maria - RS.
}

\begin{abstract}
Manuscrito:
Recebido: 20/5/2013

Corrigido: 16/6/2014

Aceito: 9/10/2014

Citation : Martello A.R., Novais T., Oleques L.C., Leal L.A., Rosa Á.A.S.da. 2015. A inserção da paleontologia no ensino fundamental em diferentes regiões do Brasil. Terræ Didatica, 11(1):33-41. <http://www. ige.unicamp.br/terraedidatica/>.
\end{abstract}

KErwords: Science teaching, common sense, methodological alternatives.
ABSTRACT : In the search for alternatives to the teaching of Paleontology the understanding of students conceptions is of great interest. This work is a quali-quantitative research with the aim of mapping the concepts of Paleontology of elementary students of Brazilian public schools. A questionnaire was used for collecting data from a total of 64 students (Jaci Paraná, 25; Jequié, 19; Santa Maria, 20). The results show that the presence of paleontological evidence or records in the region where students live does not influence their conceptions. It also showed the difficulties of the student in building a scientific conception of Palaeontology, although, they exhibited misconceptions based on views presented in the media and common sense.

\section{Introdução}

A Paleontologia é a ciência que estuda evidências da vida pré-histórica preservadas nas rochas (os fósseis), e elucida não apenas o significado evolutivo e temporal, mas também a aplicação na busca de bens minerais e energéticos (Mendes 1986). Esta importante área contribui para ampliar a compreensão da origem e evolução da vida na Terra, fazendo referência à constituição da atmosfera, decifrando a geografia e as modificações climáticas ao longo do tempo geológico.

Uma vez que os fósseis são objetos geológicos com origem em organismos do passado, a Paleontologia é a disciplina científica que estabelece uma forte ligação entre as Ciências Geológicas e as Ciências Biológicas. Além disso, auxiliam na interpretação dos ambientes antigos de sedimentação, bem como na identificação das mudanças ocorridas na superfície do planeta através do tempo geológico (Cassab 2010).

A Biologia e a Paleontologia estão intimamente interligadas, a primeira servindo como meio de afirmação nos estudos dos fósseis, já que eles são restos de organismos vivos, e a segunda, em contrapartida, fornecendo uma dimensão do tempo em que os grandes ecossistemas atuais se estabeleceram e também informações complementares às teorias evolutivas (Carvalho 2010).

Neste sentido, a Paleontologia é recomendada pelos Parâmetros Curriculares Nacionais (PCNs) como tema em Ciências para o ensino básico brasileiro, sendo frequente em muitos livros didáticos no país (Brasil, 1997). Numa perspectiva educacional, a Paleontologia tem um importante papel a cumprir, contribuindo na geração e disseminação do conhecimento ou auxiliando na compreensão de processos naturais complexos (Schwanke e Silva 2010, Cassab 2010).

Contudo, o conhecimento paleontológico ainda é muito insuficiente, restringindo-se aos centros de pesquisas, museus e discussões em meios acadêmicos (Schwanke e Silva 2010). Além disso, verifica-se que o ensino promovido na educação básica não fornece ao estudante alternativas de apropriação dos conhecimentos científicos de 
modo a compreendê-los, questioná-los e utilizá-los em situações no cotidiano (Bizzo 2002).

Atualmente, o ensino de ciências na educação básica apresenta uma visão limitada a respeito da Paleontologia, dissociando os seres do passado dos grupos atuais, acarretando a formação de concepções errôneas sobre esse assunto. $\mathrm{Na}$ busca por alternativas metodológicas para o ensino de Paleontologia, é de grande interesse o entendimento das concepções dos alunos e a influência da região fossilífera na formação desse conhecimento. As concepções são entendidas como ponto de partida e parte ativa de um processo para a construção de novos conhecimentos (Braz-da-Silva et al. 2007).

A partir da década de 1970, vários trabalhos sobre concepções de alunos e professores foram realizados com o intuito de compreender melhor os erros conceituais relacionados ao conhecimento científico (Bastos 1998). O conhecimento das concepções dos alunos é fato de grande importância para o planejamento das atividades pedagógicas, uma vez que as ideias dos estudantes sobre as estruturas biológicas muitas vezes não coincidem com o contexto cientificamente aceito (Oliveira 2005).

Entendemos por concepção um processo pessoal, por meio qual um aprendente estrutura progressivamente os conhecimentos que integra. Esse saber elabora-se, na grande maioria dos casos, num período bastante longo de sua vida, a partir da ação cultural parental, de sua prática social de criança na escola, da influência das diversas mídias e, mais tarde, de sua atividade profissional e social de adulto (clube, família, associação etc.) (Giordan e Vecchi 1996).

Os sujeitos interiorizam sua experiência cotidiana de uma forma própria e constroem seus próprios significados sobre os mais variados fenômenos. As ideias pessoais são influenciadas pela maneira de adquirir a informação. Tais ideias, muitas vezes, podem parecer incoerentes - "cientificamente incorretas" e ainda, podem manter diferentes concepções sobre um determinado fenômeno (Demczuk et al. 2007). Quando se parte do contexto de vivência do aluno, é preciso enfrentar suas concepções e que, mesmo consideradas como conhecimento tácito, podem estar no plano do senso comum, constituído por representações equivocadas ou limitadas para a compreensão e a explicação da realidade (Ramos s/d).

As visões advindas dos estudantes, do contexto de suas experiências e de seus valores culturais, devem ser reestruturadas e sistematizadas a partir das ideias ou dos conceitos que estruturam as disciplinas de referência (Paraná 2008). Algumas ferramentas metodológicas são utilizadas para mapear as concepções de professores e alunos, tais como, atividades lúdicas (Melo et al. 2007), oficinas pedagógicas (Martello e Freitas 2008) e questionários (Oleques et al. 2011).

O presente trabalho trata-se de uma pesquisa quali-quantitativa com o objetivo de mapear as concepções sobre Paleontologia de alunos do ensino fundamental de escolas públicas de regiões brasileiras.

\section{Referencial teórico}

\section{Historicidade da Paleontologia}

Desde a Pré-História, o ser humano atribuiu valores a vários objetos fossilizados os quais despertaram sua curiosidade e a valorização, provavelmente devido à sua raridade, sua semelhança com organismos vivos ou parte deles, adicionado o fator de sua textura e composição lítica (Faria 2006).

$\mathrm{Na}$ Idade Antiga, diversos pensadores levantaram hipóteses sobre a origem dos fósseis, baseadas em preceitos mais racionais. Neste período histórico, a discussão sobre a origem orgânica se fez presente, ou seja, alguns pensadores interpretavam os fósseis como tendo se originado a partir de organismos vivos, diferentemente de outros pensadores que atribuíam sua origem a forças mágicas que atuariam nas entranhas da Terra.

A discussão atravessou a Idade Média e se prolongou até a modernidade, quando o termo fossilia (fóssil) era utilizado para denominar todos os objetos petrificados obtidos por intermédio de escavação ou que se encontravam expostos na superfície da Terra (Edwards 1967).

Visões mais específicas sobre os fósseis surgiram durante o Renascimento (Ronan 2002). O francês Georges Cuvier, no seu estudo sobre os fósseis, publicou os fundamentos da paleontologia, tendo o "princípio de correlação das partes" como uma grande ferramenta, uma vez que relaciona as partes distintas dos organismos ao organismo inteiro (Eicher 1988). Cuvier explicava que as extinções ocorriam devido a catástrofes que teriam atingido a Terra. No decorrer dos anos, os estudos foram sendo aprimorados, bem como as técnicas de estratificação, o que possibilitou várias interpretações e indícios para a evolução do significado de fósseis. 
Assim, para alguns naturalistas, os fósseis que eram encontrados em diferentes estratos poderiam ser tratados como originados em diferentes épocas, e não em um único evento, como afirmavam os "diluvionistas" (Mather 1939).

Após um período, no qual os fenômenos naturais foram explicados e estudados sob diversas abordagens, é possível perceber uma maior compreensão dos fósseis e sua posição na natureza, sob um ponto de vista histórico (Faria 2006). No início do século XIX, a paleontologia inicia os primeiros passos na sociedade científica com a divulgação de pesquisa através de publicações periódicas.

A primeira citação bibliográfica referente aos fósseis brasileiros foi em 1817, anteriormente, mencionada apenas em cartas ou relatórios de viagem (Cassab 2010). Em 1818 foi criado por D. João VI, o Museu Real (atual Museu Nacional), a primeira instituição brasileira com caráter científico, dando início a uma importante coleção de fósseis encontrados em todo o País.

O termo Paleontologia foi usado na literatura geológica pela primeira vez em 1834, derivado a partir das palavras gregas: palaios $=$ antigo, ontos $=$ ser, $\log o s=$ estudo (Cassab 2010). Esta ciência tem contribuído em várias áreas do conhecimento para a compreensão da origem e evolução da vida na terra fazendo referência à composição da atmosfera, à geografia e às modificações climáticas ao longo do tempo geológico (Anelli 2002).

\section{Educação em Paleontologia}

Vivemos hoje em um mundo notadamente influenciado pela ciência. É o saber científico que proporciona o surgimento, aprimoramento e avanço de novas tecnologias que tem como finalidade essencial a geração de conhecimento, para o bem- estar da sociedade como um todo (Zucon et al. 2010). Para este autor a democratização do ensino de ciências tornou-se uma prioridade, não apenas visando a formação de cientistas, mas para proporcionar à sociedade conhecimentos fundamentais para a sua interação com o mundo.

Para Zucon et al. (2010), a Paleontologia, dentre as áreas das ciências naturais, é aquela que vem apresentando um desenvolvimento promissor nas últimas décadas, ocupando local de destaque na busca pela compreensão da evolução dos seres vivos e da história da Terra. O ensino e as abordagens da paleontologia estão inseridos nos conteúdos diretamente ou indiretamente em todos os níveis da educação no Brasil (ensino infantil, fundamental e médio) (Zucon et al. 2010). A Paleontologia, por sua vez, é introduzida por meio dos dinossauros e apenas esporadicamente permeia outros assuntos, como a origem da vida, definição e tipos de fósseis (Mello et al. 2005).

Os conteúdos sobre a Paleontologia no ensino fundamental nas escolas brasileiras se restringe as ciências da Terra usualmente agregados à física, química e geografia e, aos livros didáticos, que aportam conceitos vitais, porém pouco explorados para o conhecimento e interesse por parte das crianças, em relação à natureza na qual vivem (Mello et al. 2005).

Os PCNs recomendam a Paleontologia como tema de ciências para o ensino básico brasileiro, sendo frequente em muitos livros didáticos no País. Abordagens mais completas sobre o tema são, ainda, escassas no dia-a-dia das escolas, devido mais à deficiência dos professores do que ao desinteresse ou dificuldades de aprendizado dos alunos (Mello et al. 2005). Geralmente, há pouco interesse e dedicação das instituições na formação de professores para atuarem nos diferentes níveis da educação (Barbieri 2002).

O ensino desta área do saber é de extrema relevância, por tratar-se de uma ciência histórica que pode ser contada em uma escala de milhões de anos, e que eventos geológicos, geográficos além de processos evolutivos ocorridos no mundo biológico se registraram de diferentes maneiras (Schwanke e Silva 2010).

Apesar do processo inicial de investigação e disseminação do conhecimento paleontológico ocorrer nos centros acadêmicos, com disciplinas obrigatórias em cursos de Biologia e Geografia, ou em instituições de pesquisa, este ensino é na maioria das vezes abordado, sem maiores aprofundamentos e possibilidades de discussões, o que acarreta, consequentemente, o distanciamento da realidade dos temas relacionados à Paleontologia, além da natural frustração diante das dificuldades na compreensão por parte dos estudantes (Schwanke e Silva 2010).

A dificuldade está na forma do ensino paleontológico nas escolas, ou seja, o problema encontra-se na falta de atualização dos professores em relação ao conteúdo específico, ficando restritos apenas aos livros didáticos (Werthein e Cunha 2005). Para estes autores, isso implica em um déficit acumulado de conhecimento, levando os professores a desenvolverem uma "alfabetização 
científica" que engloba noções elementares de várias áreas científicas, sem que, na maioria das vezes, tenham sido preparados para isso.

Baseado nessa relevância, o tema Paleontologia está inserido no currículo escolar como parte integrante do bloco de conteúdo intitulado "A natureza cíclica da Natureza”, que por sua vez faz parte do tema transversal Meio Ambiente (Brasil 1999). Os temas transversais foram incorporados aos conteúdos existentes na pretensão de desenvolver a capacidade de pensar e de compreender, bem como interagir adequadamente com o mundo que nos rodeia (Moreno 1997).

Um dos aspectos levantados quando se procura defender a inclusão de temas paleontológicos na Educação Básica diz respeito ao estabelecimento de uma relação entre os conhecimentos paleontológicos e a experiência cotidiana do aluno, a fim de que a aprendizagem torne-se mais significativa (Schwanke e Silva 2010). Contudo, não basta reivindicar maior espaço para os conceitos paleontológicos nos livros didáticos e nas salas de aula. É preciso ter clareza quanto à concepção de ensino e aprendizagem a ser alcançada e buscar estratégias de aproximação que tornem os conhecimentos científicos mais significativos para os alunos (Schwanke e Silva 2010). A deficiência de conteúdo e o impacto que isso ocasiona muitas vezes são amenizados com a condução das crianças e adolescentes aos museus e exposições sobre o tema, fazendo com que elas vivenciem e assimilem a grandiosidade e a importância desse ramo das ciências naturais (Mello et al. 2005). No entanto, espaços dessa natureza (museus, salas temáticas, exposições) ainda constituem raridades em muitas cidades brasileiras, o que restringe ainda mais o acesso da população a essa cultura (Mello et al. 2005).

\section{Material e Métodos}

Esta pesquisa é de caráter quali-quantitativo. A pesquisa qualitativa tem como foco principal a exploração do conjunto de opiniões e representações sociais sobre o tema que pretende investigar (Minayo 1999). A pesquisa investigativa quali-quantitativa em educação é focada na percepção da experimentação e interpretação dos sujeitos sobre suas próprias percepções do mundo social em que estão inseridos (Bodgan e Biklen 1994).

Como instrumento de coleta de dados foi utilizado um questionário contendo um conjunto de questões pré-elaboradas. O questionário foi composto em cinco questões livres (quatro abertas e uma fechada). Para elaboração das questões foi realizada uma análise criteriosa a respeito de conteúdos relacionados a Paleontologia. O procedimento possibilita interrogar um elevado número de alunos num espaço de tempo relativamente curto, conhecer melhor as concepções dos estudantes possibilitando melhorar as metodologias de ensino (Gil 1999).

Participaram da pesquisa 64 alunos do sétimo ano do ensino fundamental. No que se refere ao critério ético, os sujeitos assinaram o Termo de Consentimento Livre e Esclarecido, garantindo o sigilo das informações e o seu anonimato, conforme orientações da resolução 196/96 do Conselho Nacional de Saúde, do Ministério da Saúde (Brasil 2006)

Para a análise dos relatos, utilizamos a técnica de análise de conteúdo norteada por Bardin (2004) em que os discursos revelam categorias: i) categoria satisfatória, em que as respostas apresentam argumentos em que se idêntica uma explicação cientifica correta, relacionadas a conceitos atualmente aceitos; ii) categoria parcialmente satisfatória, que compreende as respostas que apresentam alguma forma de conhecimento sobre o tema, mas sem explicação cientifica adequada; e por fim, iii) categoria insatisfatória, onde as respostas não apresentam explicação científica ao tema caracterizando-se ao senso comum, explicação religiosa ou respostas sem nexo.

Os nomes dos autores dos textos foram suprimidos. Por este motivo suas respostas serão identificadas por letras ( $\mathrm{A}=$ aluno) seguido de um número a ele atribuído como: A1, A2 e, assim por diante em ordem de apresentação.

O desenvolvimento da pesquisa de campo foi realizado em três cidades inseridas no contexto Paleontológico, de diferentes regiões do Brasil:

(I) Jequié-BA (19 alunos), onde à presença na escola, do 'Projeto Paleociência: itinerância e aprendizagem', com a proposta de aproximar crianças e jovens do universo científico colocando ao alcance de todos, objetos conceituais em Paleontologia. A cidade de Jequié, litologicamente, está inserida no Bloco Jequié, sendo composto de migmatitos granulíticos (Barbosa e Sabaté 2003). As rochas apresentam datações radiométricas que variam entre 2,66 a 3,4 Ga (Delgado et al. 2003). Recobrindo estas rochas, em pontos isolados e em todo o vale do rio de Contas, encontramos Coberturas Quaternárias detrito lateríticas constituídas por areia com níveis de cascalho e argila e crosta laterítica 
(Vieira et al. 2005). As rochas magmáticas e metamórficas do Bloco de Jequié, em última análise, não apresentam qualquer vestígio fossilífero, dado sua gênese e idade. A possibilidade de se encontrar fósseis na região do município de Jequié se restringe a microbacias sedimentares, localizadas em tanques naturais de acumulação de água, com sedimentos de idade que podem variar do Mioceno ao Pleistoceno (Luciano Leal, observação pessoal).

(II) Jaci Paraná-RO (25 alunos), onde está inserido o "Programa de Investigação, Monitoramento e Salvamento Paleontológico". A cidade de Jaci Paraná encontra-se situada na Formação Rio Madeira (Quaternário), rica em fósseis pleistocênicos. A grande maioria dos fósseis apresenta uma boa preservação, alguns, fortemente incrustados pela matriz de arenito ferruginizado ou "mucururu”. Nessa Formação, os registros fósseis são para a megafauna, entre eles, mamíferos (Megatherium, Stegomastodon, Toxodon, Pampatherium, Tapirus, Inia, Trichechus, Glyptodon e Neochoerus) e répteis (Testudines e Purussaurus, um crocodylomorpha) (Nascimento et al. 2005, Fortier et al. 2007). São também encontrados restos vegetais, tais como, impressões de folhas de angiospermas e caules permineralizados de grande porte, além de material palinológico (Rizzoto et al. 2006).

(III) Santa Maria-RS (20 alunos) a escola investigada não apresentava projetos relacionados à paleontologia. A região urbana de Santa Maria está situada nas Formações Santa Maria e Caturrita (ambas do Triássico). Existem jazigos fossilíferos do Grupo Rosário do Sul (fósseis animais e vegetais), da Formação Sanga do Cabral (pequenos fragmentos de vertebrados), do Membro Passo das Tropas (impressões vegetais da Flora de Dicroidium, insetos e escamas de peixes), do Membro Alemoa (vertebrados terapsídeos e arcossauromorfos, tais como: Scaphonyx fischeri, Saturnalia tupiniquin e Staurikosaurus pricei) e da Formação Caturrita (lenhos permineralizados "madeira pedra", dinossauro prossaurópode) (Da Rosa 2004).

\section{Resultados e Discussão}

Esta seção está organizada em duas partes interrelacionadas. Na primeira parte apresentamos os saberes paleontológicos dos participantes e na segunda parte, o conhecimento destes sobre os fósseis da região.

\section{Saberes paleontológicos}

Neste tópico foram analisadas as concepções dos alunos sobre a Paleontologia e fósseis. $\mathrm{Na}$ primeira questão "O que você entende por Paleontologia?" as concepções estão sumariadas na Tabela 1.

No geral, as concepções apresentadas pelos alunos aproximaram-se dos elementos presentes no conceito científico, tais como, restos e vestígios, animais ou vegetais pré-históricos, fóssil e passado geológico.

A categoria satisfatória apresentou resultados semelhantes entre os alunos das três regiões, compreendendo cerca de $20 \%$ na cidade de Santa Maria, 21\% na cidade de Jequié e 24\% na cidade de Jaci Paraná. Na categoria parcialmente satisfatória as respostas foram mais restritivas ao conhecimento dos alunos, em relação à ciência que estuda apenas um tipo de fóssil. $\mathrm{Na}$ cidade de Santa Maria esta categoria compreendeu as respostas de $50 \%$ dos estudantes, em Jequié $42,1 \%$ e em Jaci Paraná cerca de 32\% das respostas.

$\mathrm{Na}$ categoria insatisfatória, os alunos demonstraram possuir pouco conhecimento sobre o termo Paleontologia. Na cidade de Santa Maria 30\% dos alunos não responderam. $\mathrm{Na}$ cidade de Jequié, $31,6 \%$ dos alunos não responderam, e 5,3\% responderam de forma indiferente. Em Jaci Paraná, 36\% não souberam responder, responderam de forma restritiva, $24 \%$ mais ampla e $8 \%$ foram indiferentes em suas respostas.

Tabela 1. Categorização das concepções sobre Paleontologia apresentadas por alunos das três regiões investigadas.

\begin{tabular}{c|c}
\hline Categorias & Concepções dos alunos \\
\hline Satisfatória & - "É o estudo dos fósseis" (A1) \\
\hline $\begin{array}{c}\text { Parcialmente } \\
\text { satisfatória }\end{array}$ & - "É o estudo sobre fósseis, ossos e vestígios" (A2) \\
\hline Insatisfatória & - "É o estudo dos dinossauros" (A3) \\
\hline
\end{tabular}


O que você entende por fósseis?

Na segunda questão solicitamos a definição da palavra fóssil, e para a análise das respostas foram utilizamos as mesmas categorias da questão anterior. Para as respostas classificadas como satisfatórias, nos baseamos como critério, o conceito mais próximo do estabelecido cientificamente, sendo "restos de animais e vegetais ou evidências de suas atividades que ficaram preservados nas rochas e outros materiais como o gelo, âmbar e o asfalto" (CASSAB, 2010). Para as respostas parcialmente satisfatórias, os alunos basearam-se em definir fósseis a um tipo especifico de vestígio, sem levar em consideração a diversidade fossilífera. E, na categoria insatisfatória, associaram a outros tipos de vestígios ou falta de conhecimento sobre essa questão (Tab. 2).

Em Santa Maria, 15\% não souberam responder e os demais (85\%) responderam de forma parcialmente satisfatória, associando os fósseis na maioria das vezes aos dinossauros. Em Jequié, 5,2\% responderam de forma satisfatória, $15,8 \%$ de forma insatisfatória e $79 \%$ de forma parcialmente satisfatória. Na cidade de Jaci Paraná, 20\% não souberam responder, $4 \%$ de forma satisfatória e $76 \%$ de forma parcialmente satisfatória.

Podemos inferir que, mesmo com o desenvolvimento de projetos com a temática Paleontologia, as concepções dos alunos nas cidades de Jequié e Jaci Paraná não apresentaram diferença das apresentadas pelos alunos não contemplados com projetos e tampouco foram suficientes para explicar o questionamento realizado. Isto deve-se a falta de entendimento ou abstração do significado de conceito científico aprendido durante o cotidiano escolar.

Diante das concepções mapeadas através das questões iniciais, foi possível identificar, que os estudantes das três regiões, de forma geral, tem conhecimento prévio parcialmente satisfatório para caracterizar a Paleontologia e seus objetos de estudos (jazida fossilífera e fóssil).

Entretanto, todas as definições apresentam conceitos populares e de senso comum, muitas vezes adquiridos por influência da mídia e conversas no cotidiano. Esta situação sugere que os mesmos não possuem familiaridade com o termo científico, sendo comprovadas pelo alto percentual de respostas parciais, e muitas vezes voltadas aos "dinossauros", que é o contato mais "popular" e próximo para esses alunos, devido aos filmes, novelas, programas televisivos, brinquedos, livros didáticos e paradidáticos.

\section{Conhecimento de fósseis na região}

$\mathrm{Na}$ segunda parte apresentamos a análise das questões referentes a influencia da região fossilífera, onde esses alunos estão inseridos, sobre o conhecimento prévio apresentado pelos mesmos.

Tem conhecimento de algum fóssil da sua região? Cite-os.

A terceira e a quarta questão do questionário foram destinadas para elucidar o conhecimento dos alunos sobre algum fóssil encontrado na sua região. Em Santa Maria-RS, 55\% dos alunos responderam que possuíam conhecimento sobre a presença de fósseis para a região. $\mathrm{Na}$ cidade de Jequié-BA, 26\% dos alunos responderam possuir ter conhecimento e 32\% responderam não ter nenhum conhecimento sobre fósseis na região. Em Jaci Paraná-RO, 44\% dos alunos responderam possuir algum tipo de conhecimento sobre fósseis encontrados na sua região.

Em continuidade à questão anterior, solicitamos aos alunos que citassem os fósseis que eles têm conhecimento de terem sido encontrados na sua região (Tab. 3).

Tabela 2. Categorização das respostas dadas pelos alunos referente aos fósseis.

\begin{tabular}{c|c}
\hline Categorias & Concepções dos alunos \\
\hline $\begin{array}{c}\text { Satisfatória } \\
\text { Parcialmente } \\
\text { satisfatória }\end{array}$ & - "Restos de animais e plantas" (A6) \\
\hline $\begin{array}{c}\text { - "Fósseis eu entendo que e as fezes e uns objetos com desenhos na pedra resto de ossos" } \\
\text { (A7) }\end{array}$ & - "São ossos de dinossauros" (A8) \\
\hline Insatisfatória & - "São os animais pré histórico" (A9) \\
\hline
\end{tabular}


Tabela 3. Categorização das representações sobre fósseis pelos alunos

\begin{tabular}{|c|c|c|c|}
\hline Regióoes & \multirow{2}{*}{ Jaci Paraná } & \multirow{2}{*}{ Jequié } & \multirow{2}{*}{ Santa Maria } \\
\hline Categorias & & & \\
\hline Satisfatória & $\begin{array}{c}\text { - "Troncos de árvores } \\
\text { petrificadas" (A12) } \\
\text { - "Tatu gigante, preguiça } \\
\text { gigante, impressão de folhas e } \\
\text { plantas nas pedras" (A13) }\end{array}$ & $\begin{array}{c}\text { - "Fósseis de peixe petrificado" } \\
\text { (A14) } \\
\text { - "Conchas petrificadas, peixes } \\
\text { petrificados, impressão de folhas } \\
\text { de plantas na pedra" (A15) } \\
\text { - "Peixes insetos gravados na } \\
\text { pedra" (A16) }\end{array}$ & $\begin{array}{c}\text { - "Troncos de árvores } \\
\text { petrificados e folhas na } \\
\text { pedra” (A17) } \\
\text { - "Fósseis de dinossauros" } \\
\text { (A18) }\end{array}$ \\
\hline $\begin{array}{l}\text { Parcialmente } \\
\text { satisfatória }\end{array}$ & $\begin{array}{l}\text { - "Bem eu já ouvir falar em } \\
\text { ossos de dinossauros" (A19) } \\
\text { - "Eu vi um fóssil de uma vaca } \\
\text { que já tinha morrido há muito } \\
\text { tempo" (A20) }\end{array}$ & $\begin{array}{c}\text { - "Caramujos peixes folhas etc. } \\
\text { Insetos conchas petrificados" } \\
\text { (A21) }\end{array}$ & \\
\hline Insatisfatória & $\begin{array}{c}\text { - "Na usina jirau” (A22) } \\
\text { - "Já acharão um osso de } \\
\text { tartaruga marinha no paio" } \\
\text { (A23) }\end{array}$ & - "Insetos peixes e tatu” (A24) & - “Santiago" (A25) \\
\hline
\end{tabular}

Você identifica quais fósseis estão presentes na sua região?

$\mathrm{Na}$ quinta questão foi apresentada aos alunos uma lista de múltiplas escolhas com exemplos de fósseis de diferentes épocas e regiões, sendo solicitado que escolhessem as alternativas com fósseis presentes na sua região e conhecidos por eles, indiferente da fonte de informação (Tab. 4).

Com os resultados aqui obtidos evidenciamos que as pesquisas e trabalhos de extensão realizados no âmbito da Paleontologia nas cidades de Jaci
Paraná e Jequié estão presentes nas concepções apresentadas pelos alunos. Em Santa Maria, apesar da riqueza fossilífera, poucas são as atividades realizadas nesse aspecto com alunos do ensino fundamental, propiciando a carência de conhecimento nesta área.

Piaget (1967) diz que o desenvolvimento dos saberes está bastante relacionado à interação do indivíduo com o meio físico e com o contexto sócio-cultural nos quais se encontra inserido. Assim, constatamos que, com a implantação do projeto "Centro de Informação Itinerante/Subprojeto Paleontologia” nas escolas do município de

Tabela 4. Frequência (\%) das respostas dos alunos sobre a presença de fósseis nas regiões de Jaci Paraná-RO (JP), Jequié-BA (JQ) e Santa Maria-RS (SM)

\begin{tabular}{l|c|c|c}
\multicolumn{1}{c|}{ Fósseis citados } & JP (\%) & JQ (\%) & SM (\%) \\
\hline Troncos de árvores petrificados & 32 & 21 & 25 \\
\hline Ossos de dinossauros & 16 & 10,5 & 70 \\
\hline Ossos de mamíferos gigantes & 12 & 5,2 & 20 \\
\hline Impressão de folhas de plantas & 20 & 52,6 & 15 \\
\hline Pegadas de dinossauros & 0 & 10,5 & 20 \\
\hline Peixes petrificados & 16 & 47,3 & 15 \\
\hline Pterossauros & 0 & 5,2 & 20 \\
\hline Preguiça gigante & 16 & 0 & 20 \\
\hline Tatu gigante & 20 & 15,8 & 15 \\
\hline Elefante pré-histórico & 8 & 0 & 25 \\
\hline Insetos gravados na pedra & 20 & 47,3 & 20 \\
\hline Conchas petrificadas & 12 & 15,8 & \\
\hline
\end{tabular}


Jaci Paraná devido à construção da Usina Hidrelétrica de Jirau, os alunos tiveram oportunidade de visualizar e entender o surgimento e os tipos de fósseis encontrados na região. Com isso, apresentaram concepções mais próximas aos conceitos científicos relacionados aos conteúdos presentes na Paleontologia.

Em Jequié e Santa Maria, alguns alunos descreveram corretamente alguns tipos de fósseis, tais como: árvores petrificadas, peixes, tartaruga, etc. Embora, algumas respostas apresentadas especificamente para os alunos de Santa Maria, não foi possível definir nenhum significado, pois tanto na literatura quanto nos conhecimentos de profissionais, nenhum fóssil encontrado foi nomeado por "Santiago", desconhecendo o motivo dessas respostas. Isto pode ser resultado de uma sobreposição de informações da mídia, acarretando na formação de concepções errôneas pelos alunos e mantidas por falta de acesso ao conhecimento apropriado.

De acordo com as concepções apresentadas, o resultado não apresentou diferença significativa entre os alunos das diferentes regiões, corroborando com o estudo de Bizzo et al. (2008) afirmando que o contato direto com fósseis por si só não pode assegurar a percepção do tempo geológico e dos enormes lapsos de tempo requeridos na fossilização e processos correlatos

\section{Considerações finais}

De maneira geral foi possível visualizar as concepções dos alunos a respeito da temática Paleontologia, sendo possível inferir que o meio influencia na aquisição dos saberes que vão ser formados ao longo da vida, inclusive para o conteúdo da ciência paleontologia.

Os resultados obtidos mostram que as regiões que desenvolvem atividades de ensino sobre Paleontologia, promovem uma vivência mais próxima e a concepção sobre a temática está mais presente nos alunos. Evidenciamos, também, as dificuldades que os estudantes possuem em conceituar de forma cientifica a Paleontologia, embora, consigam apresentar concepções pouco satisfatórias e baseadas no senso comum.

A criação e inserção de projetos nas escolas são importantes, pois mobilizam os alunos, promovendo maior interesse por parte deles, sendo considerada uma excelente estratégia de ensino. Cabe salientar que pesquisas qualitativas em Paleontologia precisam ser feitas continuamente, na tentativa de captar e explorar a realidade sempre em construção e o momento histórico-cultural vigente. Os dados devem servir de referência para o desenvolvimento de trabalhos relacionados com a Paleontologia, tornando o assunto mais próximo a realidade e desmitificando pré-concepções originadas pela mídia e pelo senso comum. Isto reafirma a necessidade da implantação de projetos em parcerias realizadas por universidades com instituições de ensino da educação básica nas diferentes cidades.

\section{Referências}

Anelli L.E. 2002. O passado em suas mãos: guia para coleção de réplicas. São Paulo: EDUSP.

Barbieri M.R. 2002. Laboratório de Ensino de Ciências. 20 anos de história. Ribeirão Preto: Holos.

Barbosa J.S.F., Sabaté P. 2003. Colagem Paleoproterozóica de placas arqueanas do Cráton do São Francisco na Bahia. Rev. Bras. Geoc., 33:3-6.

Bardin L. 2004. Análise de conteúdo. Lisboa: Edição 70.

Bastos F. 1998. O ensino de conteúdos de História e Filosofia da Ciência. Ciência E Educação, 5(1): 55-72.

Bizzo N. 2002. Ciências fácil ou difícil? 2.ed. São Paulo: Ática.

Bizzo N., Almeida A.V., Falcão J.T.R. 2008. A compreensão de estudantes dos modelos de evolução biológica: duas aproximações. In: Mortimer E.F. org. 2008. Atas do VI Encontro Nacional de Pesquisa em Educação em Ciências, Florianópolis: Abrapec.

Bodgan R., Biklein S. 1994. Investigação qualitativa em educação. Portugal: Porto.

Brasil. Ministério da Educação. 1997. Parâmetros Curriculares Nacionais: ensino médio: ciências da natureza, matemática e suas tecnologias. Brasília: Secretária da educação Média e Tecnológica.

Brasil. Ministério da Educação. 1999. Parâmetros Curriculares Nacionais: Ensino Médio. Brasília: Secretária da educação Média e Tecnológica.

Braz da Silva A.M.T., Mettrau M.B., Barreto M.S.L. 2007. O lúdico no processo de ensino-aprendizagem das ciências. Rev. Bras. Est. Pedag., 88(220):445-458.

Carvalho I.S. 2010. Paleontologia - 1. 2.ed. Rio de Janeiro: Interciência.

Cassab R.C.T. 2010. Objetivos e Princípios. In: Carvalho I.S. ed. 2010. Paleontologia. Rio de Janeiro: Interciência, p.3-11.

Da Rosa Á.A.S. 2004. Sítios Fossilíferos de Santa Maria, RS, Brasil. Ciência E Natura, 26(2):75-90.

Delgado I.M., Souza J.D., Silva L.C., Silveira Filho N.C., Santos R.A., Pedreira A.J., Guimarães J.T., Angelim L.A.A., Vasconcelos A.M., Gomes I.P., Lacerda Filho J.V, Valente C.R., Perrotta M.M., Heineck C.A. 2003. Geotectônica do Escudo 
Atlântico. In: Bizzi L.A., Schobbenhaus C., Vidotti M., Gonçalves J.H. eds. 2003. Geologia, Tectônica e Recursos Minerais do Brasil. Brasília: CPRM - Serviço Geológico do Brasil, 692 p.

Demczuk O.M., Sepel L.M.N., Loreto E.L.S. 2007. Investigação das concepções espontâneas referentes a ciclo de vida e suas implicações para o ensino nas séries iniciais. Revista Electrónica de Enseñanza de las Ciencias, 6(1):117-128.

Edwards W. 1967. The early history of palaeontology. London: British Museum.

Eicher D.L. 1988. O Tempo Geológico. São Paulo: Edgard Bluncher.

Faria F.F.A. 2006. O despontar de um paradigma na Paleontologia. Filos. e Hist. Biol., 1:125-136.

Fortier D.C., Nascimento, E.R., Holanda, E.C. 2007. Primeiro registro de crocodylidae para a Formação Rio Madeira, Pleistoceno superior, estado de Rondônia. Paleontologia em Destaque, 57.

Gil A.C. 1999. Métodos e técnicas de pesquisa social. 5.ed. São Paulo: Atlas.

Giordan A., Vecchi G. 1996. As origens do saber: das concepções dos aprendentes aos conceitos científicos. Porto Alegre: Artes Médicas.

Martello A.R., Freitas D.S. 2008. Oficina pedagógica sobre o tempo geológico: uma contribuição ao ensino de ciências. Perspectiva, 32:201-209.

Mather K.F. 1939. A source book in geology. New York: McGraw-Hill.

Mello L.S. 2010. Canta cantos: uma forma alternativa de se fazer geografia. Belo Horizonte: UFMG.

Mello F.T., Mello L.H.C., Torello M.B.F. 2005. A Paleontologia na Educação Infantil: alfabetizando e construindo o conhecimento. Ciência e Educação, 11(3):395-410.

Melo D.J., Bastos A.C.F.B., Rodrigues V.M.C., Monção V.M. 2007. Desenvolvimento de atividade lúdica para o auxílio do ensino e divulgação científica da paleontologia. An. Inst. Geoc. UFRJ, 30(1):73-76.

Mendes J.C. 1986. Paleontologia básica. São Paulo: USP.

Minayo, M.C.S. 1999. Pesquisa social: teoria, método e criatividade. Petrópolis: Vozes.

Moreno M. 1997. Temas transversais: um ensino voltado para o futuro. In: Busquets M.D. ed. 1997. Temas transversais em educação: Bases para uma for- mação integral. São Paulo: Ática. p.19-59.

Nascimento E.R., Holanda E.C., Góis F., Cozzuol M.A. 2005. O estado da arte dos registros fossilíferos do Quaternário de Rondônia, Brasil. Paleontologia em Destaque, 49.

Oleques L.C., Bartholomei-Santos M.L., Boer N. 2011. Evolução biológica: percepções de professores de Biologia. Revista Electrónica de Enseñanza de las Ciencias, 10(2):243-263.

Oliveira S.S. 2005. Concepções alternativas e ensino de Biologia: como utilizar estratégias diferenciadas na formação inicial de licenciados. Educar, 26:233-250.

Piaget J. 1967. A construção do real na criança. Rio de Janeiro: Zahar.

Ramos M.N. s/d. A contextualização no currículo de ensino médio: a necessidade da crítica na construção do saber científico. Mimeo.

Ronan C. 2002. História ilustrada da ciência. São Paulo: Zahar.

Rizzoto G.J., Cruz N.M., Oliveira, J.G., Quadros, M.L.E.S., Castro, J.M. 2006. Paleoambiente e o registro fossilífero pleistocênico dos sedimentos da Formação Rio Madeira. In: Simpósio de Geologia da Amazônia, IX, 2006 Belém, Sociedade Brasileira de Paleontologia.

Schwanke C., Silva M.A.J. 2010. Educação e Paleontologia. In: Carvalho I.S. (Ed.) Paleontologia. v.2. Rio de Janeiro: Interciência. p.123-130.

Vieira Â.T., Melo F., Lopes H.B.V., Viegas J.C., Guimarães J.T., Costa J.M., Bomfim L.F.C., Couto P.A.A., Benvenuti S.M.P. 2005. Projeto Cadastro de Fontes de Abastecimento por Água Subterrânea Diagnóstico do Município de Itaberaba - Bahia. Salvador: CPRM/PRODEEM.

Werthein J., Cunha C. 2005. Educação científica e desenvolvimento: o que pensam os cientistas. Brasília: UNESCO/Instituto Sangari.

Zucon M.H., Vieira F.S., Prazeres M.F.F., Dantas M.A.T. 2010. O ensino de Paleontologia e a percepção dos alunos do curso de Biologia da Universidade Federal de Sergipe. v.1. Anais do IV Colóquio Intern. Educ. e Contemporaneidade. Aracaju: EdUFS.

Roldão M. 2000. Formar professores. Os desafios da profissionalização e o currículo. Aveiro: Univ. Aveiro.

RESUMO : Na busca por alternativas para 0 ensino sobre Paleontologia é de grande interesse 0 entendimento das concepções dos alunos. Este trabalho resulta de uma pesquisa qualiquantitativa com o objetivo de mapear as concepções sobre Paleontologia dos alunos do ensino fundamental de escolas públicas brasileiras. Para a coleta de dados utilizou-se um questionário, sendo aplicado a um total de 64 alunos (Jaci Paraná, 25; Jequié, 19; Santa Maria, 20). 0s resultados obtidos mostram que a presença de evidências ou registros paleontológicos na região onde os alunos estão inseridos não influencia nas concepções apresentadas pelos mesmos. Evidenciou-se também, as dificuldades que os estudantes possuem em conceituar de forma cientifica a Paleontologia, embora consigam apresentar concepções equivocadas baseadas na mídia e no senso comum.

PALAVRAS-CHAVE: Ensino de ciências, senso comum, alternativas metodológicas. 